\title{
معايير اختيار قصائد المبِّ عند فاروق شوشة
}

\section{أ. د. فـاضل عبود التهميهي

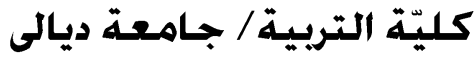

مقدمهة:

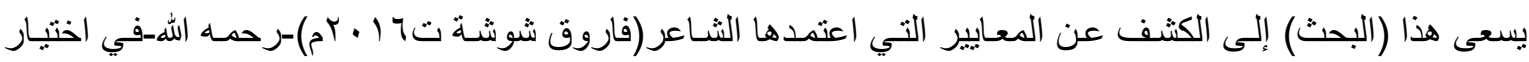

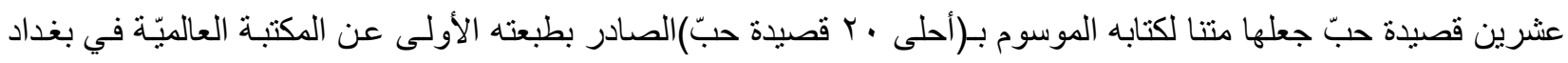

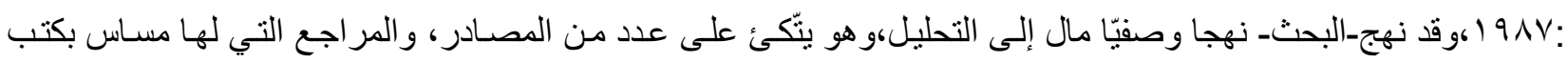
الاختيار ات، وطر ائق تقديم الشعر.

اعتمد الثاعر (فاروق شوشة) معايير مهمّة في تأليف الكتاب، منها مـا صرّ حهـا، ومنها مـا لم يصرّح، وكانت-

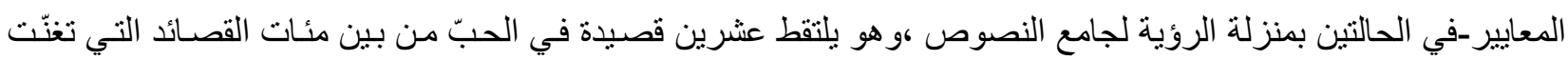

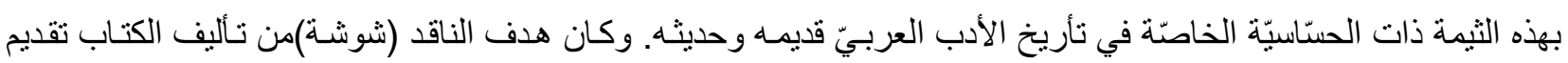

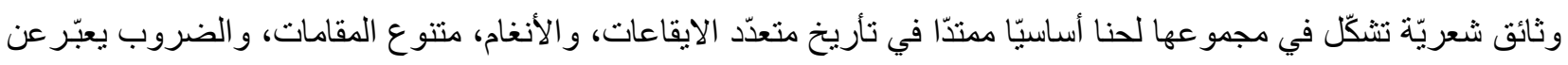
تجربة الثاعر العربيّ،وهو يعلن عن انتمائه إلى فضاء العاطفة، فضلا عن تقديم منن شعريّ متجانس الرؤى.

العرض:

تمثّل كتب الاختيارات في تأريخ الأدب العربي نمطا من الجهد الذي يعمد فيه صاحبها إلى جمع أنشعار معيّنة يوحّدها

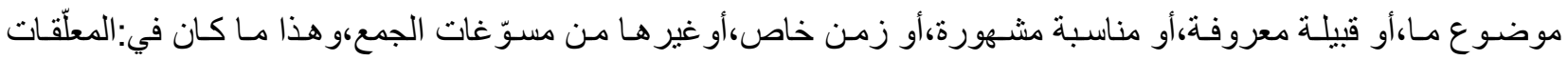

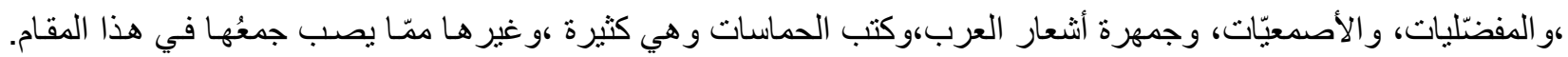

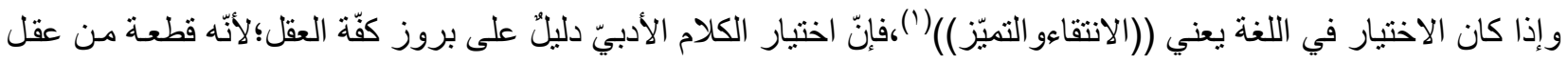

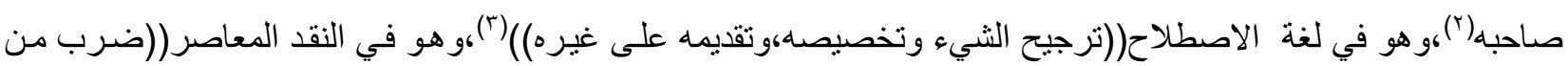

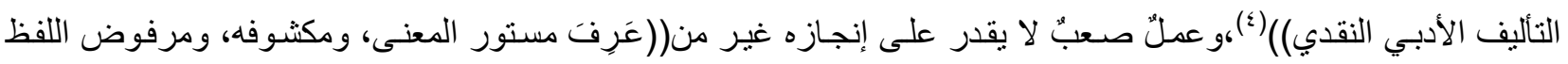

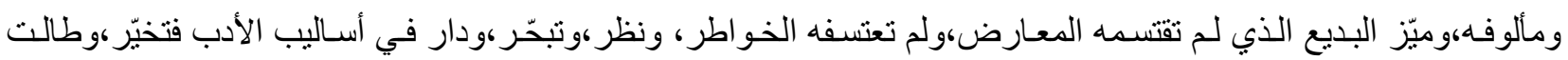

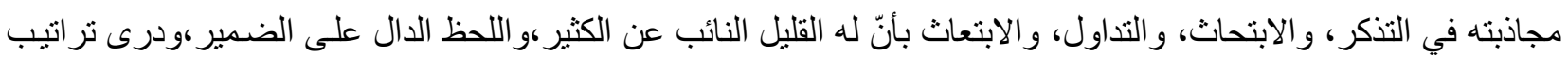

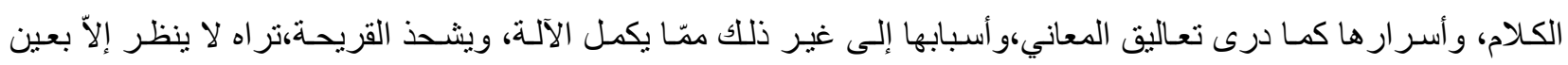

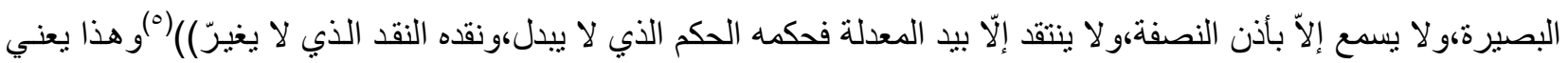

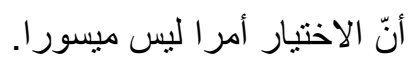

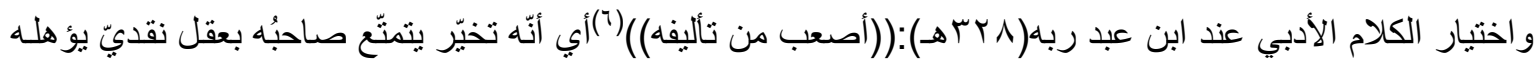

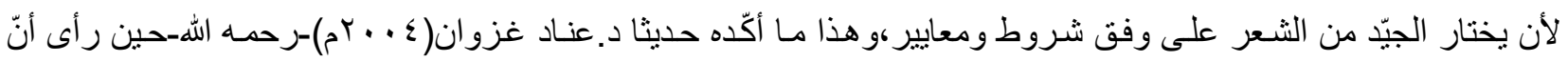

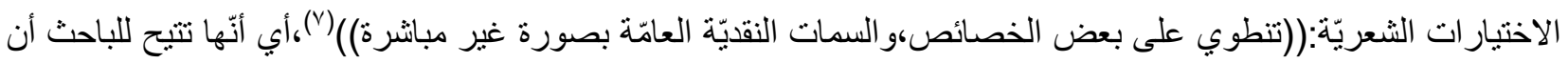

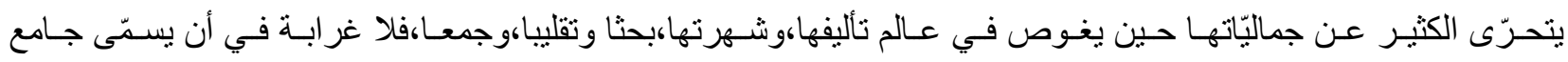

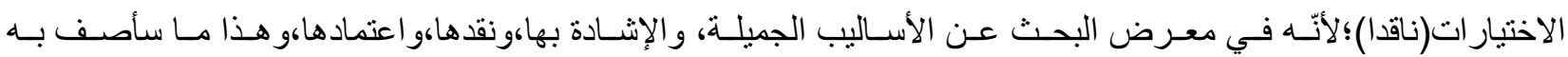
الشاعر(فاروق شوشة)بعد الآن. 
وكتب الاختيار ات في تأريخ الأدب العربي لها من الأهيّة الكبرى؛((لأنّها تقوم في الأصل على تحكيم الذوق في

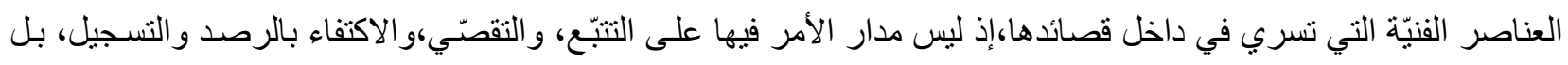

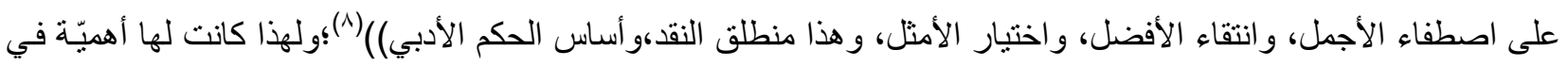
تأريخ التأليف عند العرب.

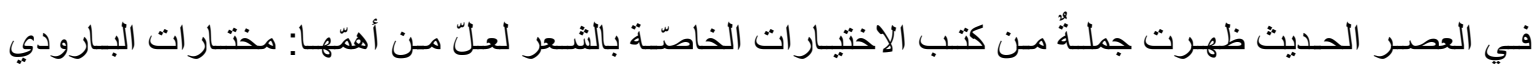
تحقيق:مجمو عة من الباحثين بإنشر اف د.محم مصطفى هدّارة الصـادرة عن مؤسّّسة جائزة عبد العزيز سعود البابطين للإبداع

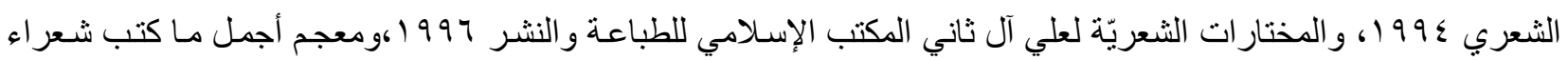

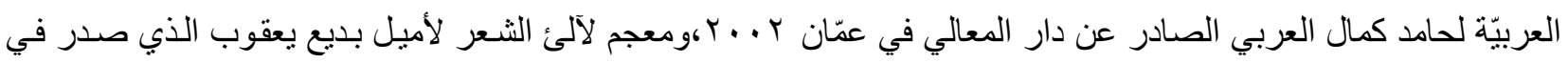

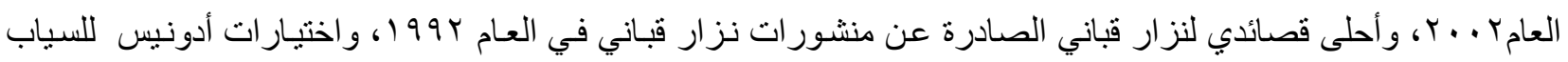

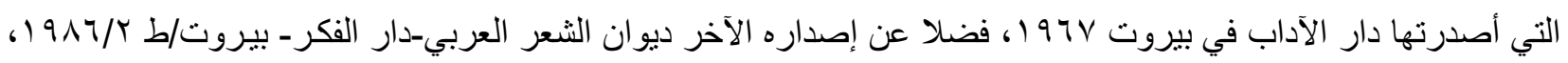

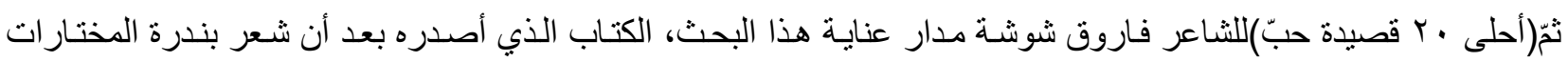

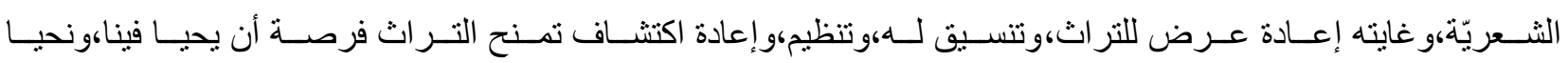

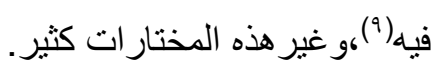

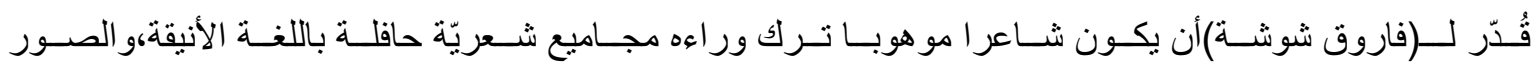

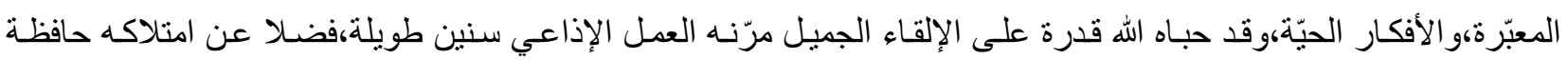

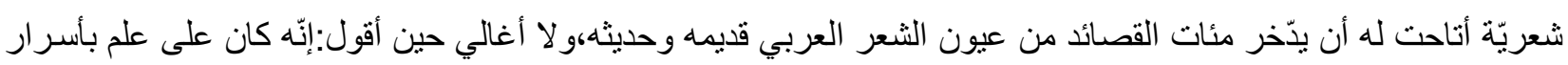

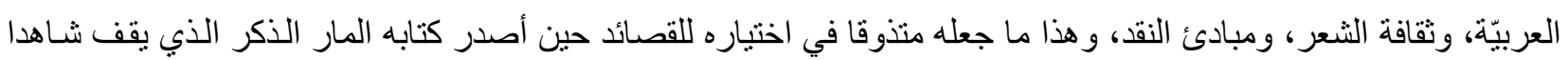

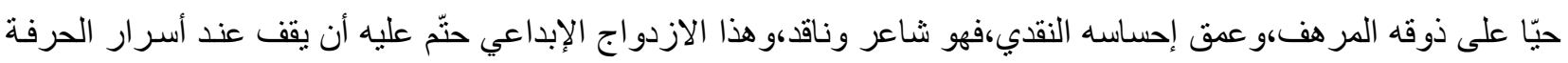

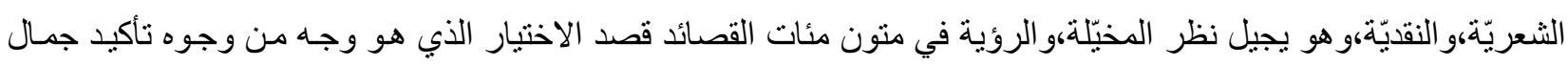

وَصَفَ (شوشة)كتابه بأنّه رحلة مع عشرين قصيدة حب،بداء من العصر الجاهلي و انتهاء بالعصر الحديث،فاختار ست

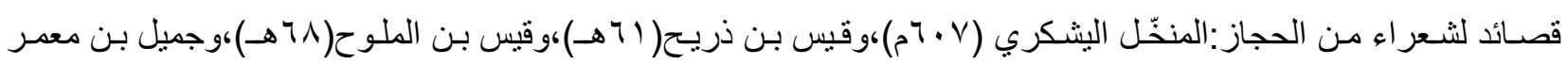

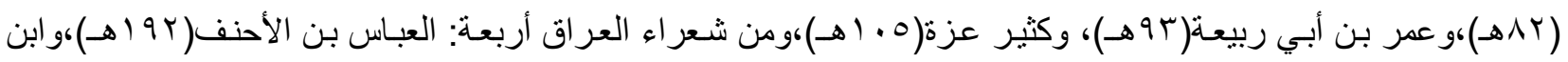

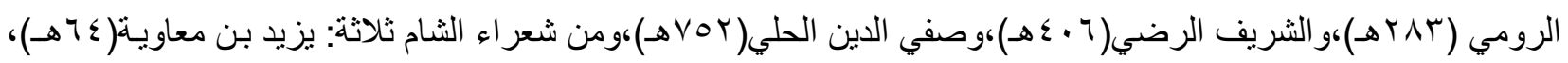

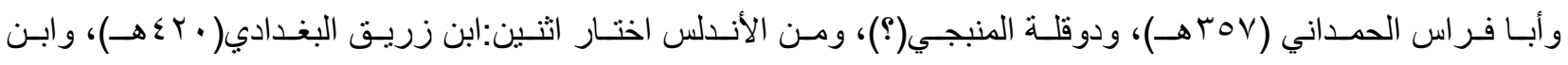

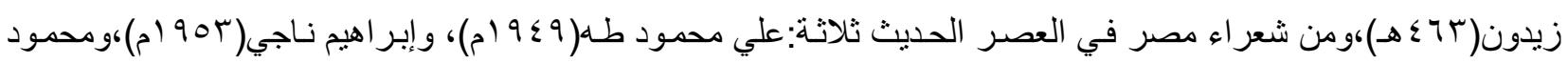

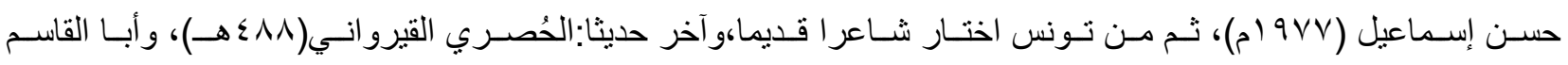

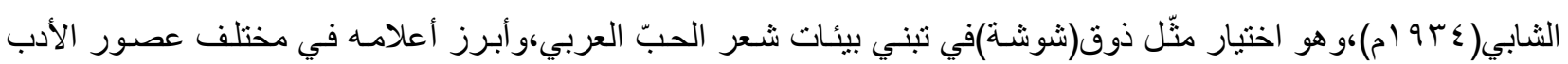
العربي. يؤخذ على الناقد(شوشة)أنّ ترتيب الثعراء في منن الكتاب وقع في إثنكال يجدر التنويه به على الرغم من أنّ المؤلف

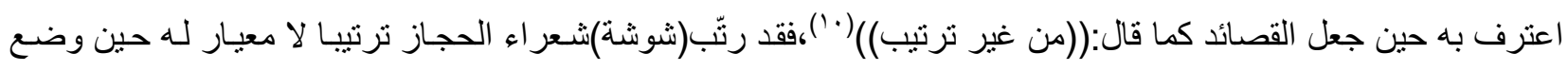

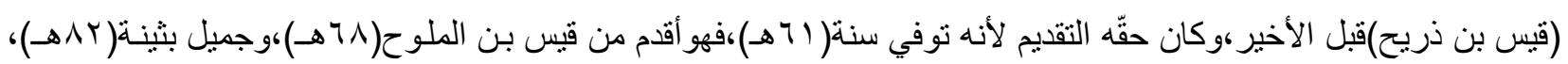




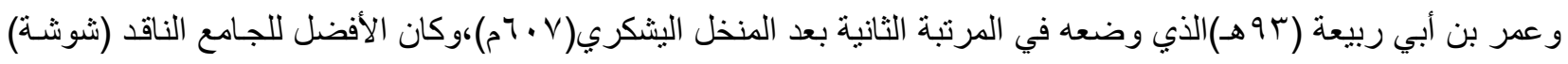

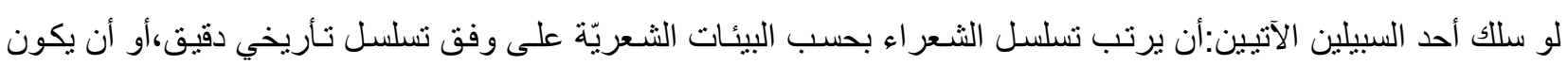
الترتيب بحسب قدم الوفاة للجميع و هو الأفضل.

إنّ السؤال الدائر في فلك هذا (البحث):مـا المعايير التي اعتمدها الناقد(فاروق شوشـة)وهو يلتقط عشرين قصيدة في

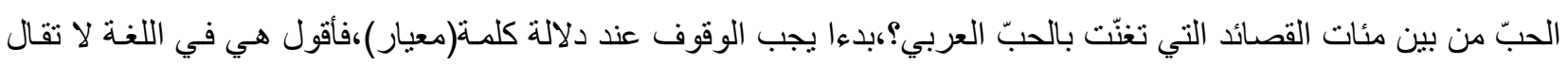

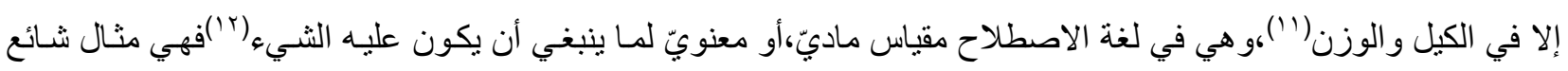

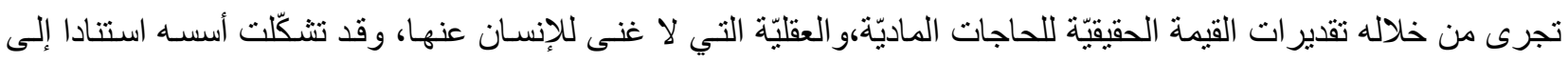
اتفاقات جمعيّة يحكمها زمان محدد ومكان.

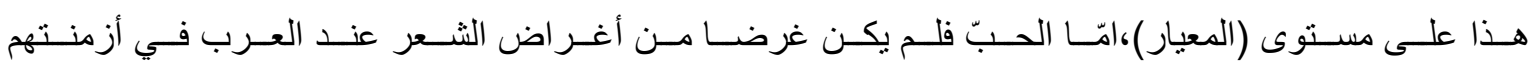
كلّها، إنّماهو(ثيمة)أي(موضوع)قديم-جديد يزوّد الإنسان بطاقة عالية الإحساس في وجوده، ويربطه بتيار من العلاقات الانفعاليّة

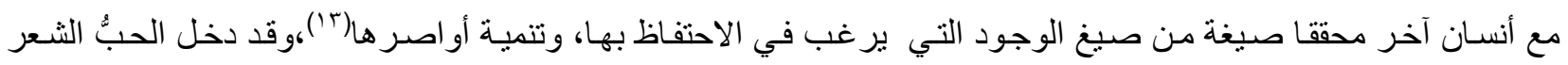

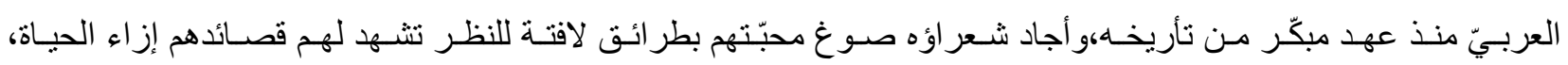

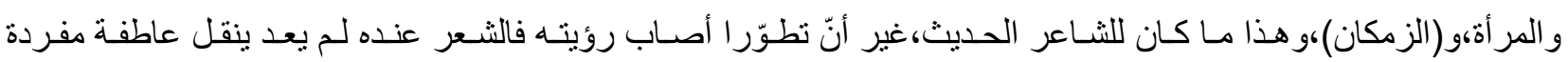

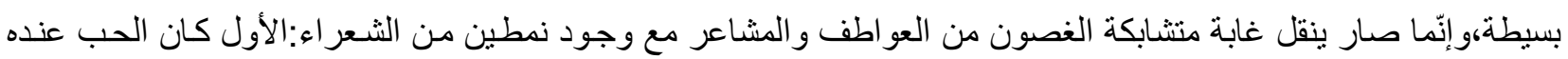

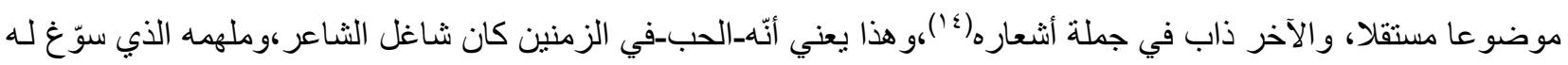
كتابة أجمل الأشعار.

\section{المعايير الأولى:}

نعود إلى السؤ ال السـابق لنذكر أنّ مقدمة(شوشـة)للكتاب تفوّهت بثلاثـة معايير بنسى من خلالها مقاييس اختيار اتـه،

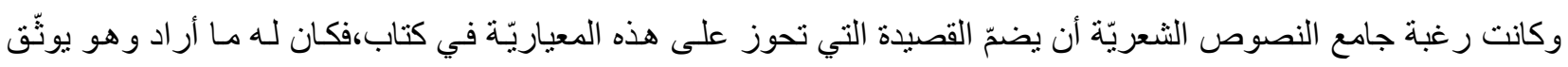

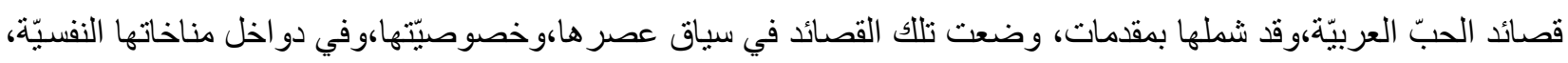
والتأريخيّة في إطار حركة الثعر العربي ودور انه المستمر (10). إنّ القر اءة المتأنية لمنن الكتاب في ضوء المعايير السابقة تحبل على أنّه نوقف مليّا عند تلك المعايير،وحاول أن يجد

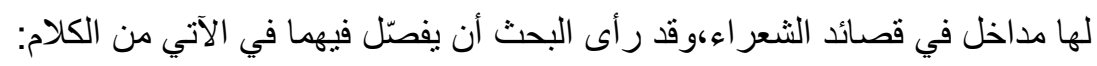

\section{1ـ هعيار الشاعر العاشق الذي ينطق بصدق العاطفة والشعور(17):}

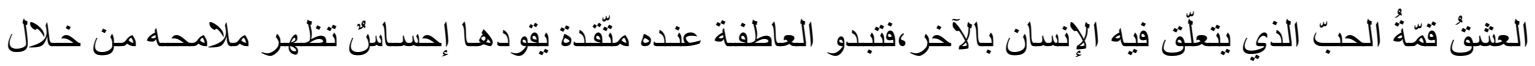

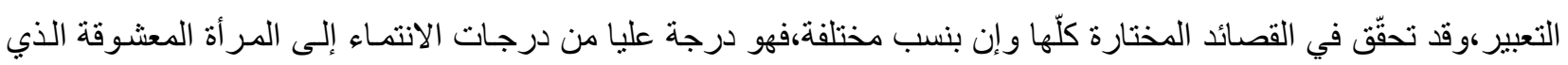

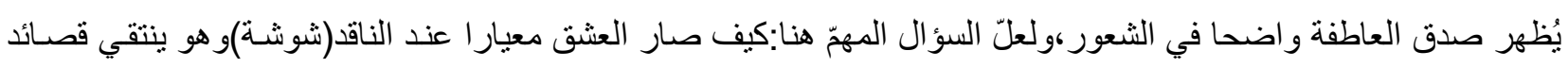

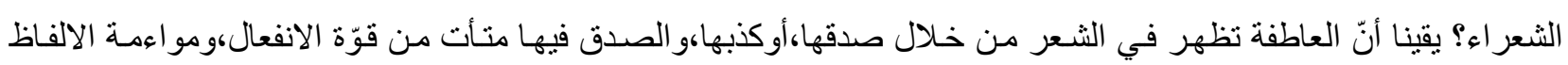

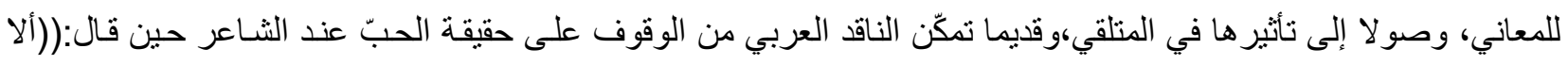

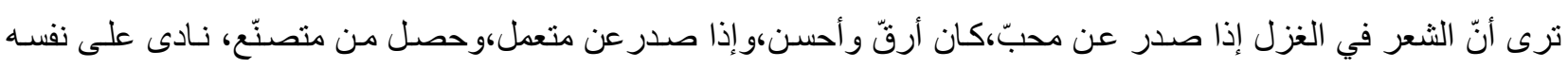

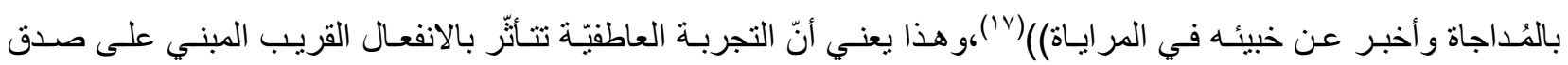

\section{$-19 \varepsilon-$}


المعاناة،وقيام التجربة،وحصول الاستجابة الفنيّة القائمـة على ردّ فعل المستجيب نفسيّا،و الثـعر-كمـا هو معروف-نتاج التخيّل الذي عماده(الصدق)ليس بمفهومه التقليدي المبني على القرب من الحقيقة،إنّما بمفهوم الوعي الجمالي المرتبط بالإحساس الذي معتي يدركه الثاعر،و هو في أعلى تحو لاته النفسيّة المتّجهة صوب تمثيل الحياة، وتوثيق إثكالياتها المختلفة عبر المخيّلة. ترى كيف جعل الناقد(فاروق شوشة)العشق الذي ينطق بصدق العاطفة والثـعور معيار ا حاكما في اختيار قصـائد

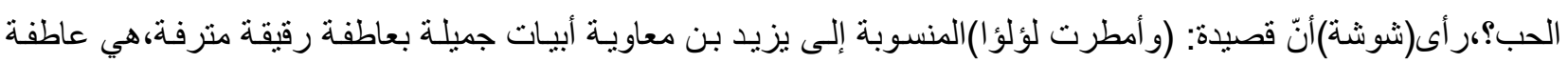

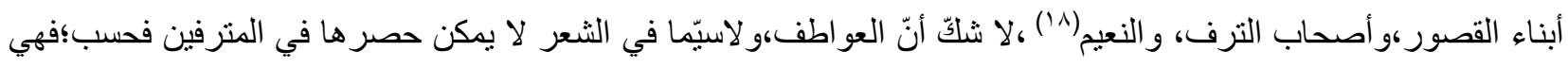

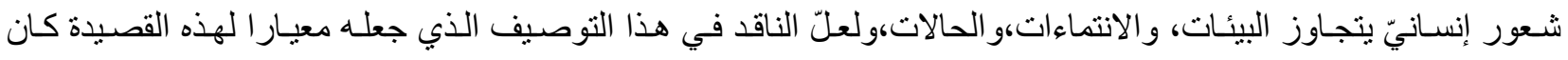

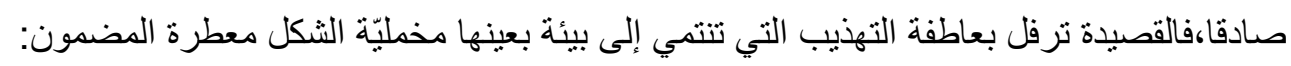

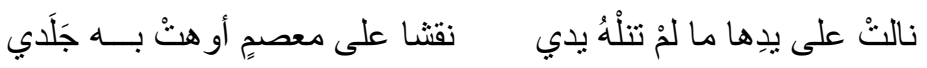

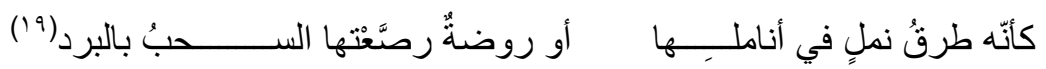

فالشاعر يقف من خلال القصيدة مبهور ا بحبّ المر أة بعد أن أدرك أن لحظة الحبّ بدأت من مر أى نقش(وشم)على في معصم يدها،وقد أضفى عليها جمالاً جعله غير قادر على تمالك زمام روحسه،فهو في أدنى حالات الوله،فاستعان بالتشبييه

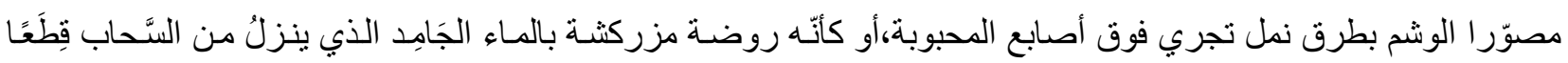

هذا التشبيه التصويري منح المتلقي دلالة غير تقليديّة فيها شيء من الغر ابة، فضلا عن المبالغة التي أسهمت في تأويل

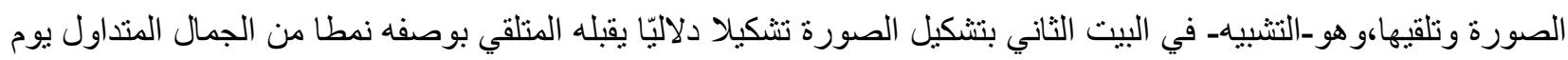

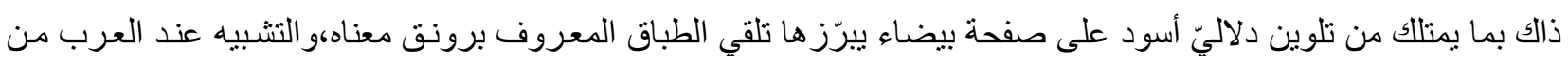

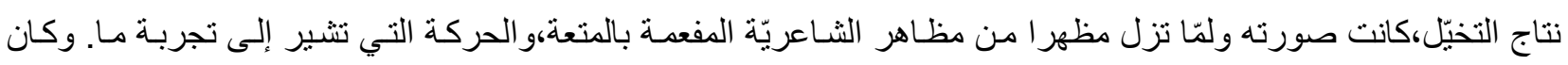

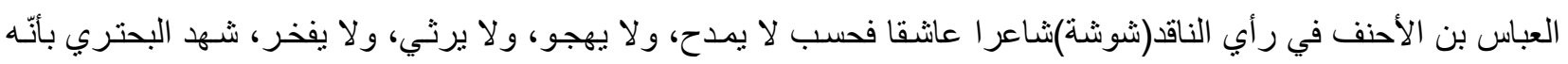

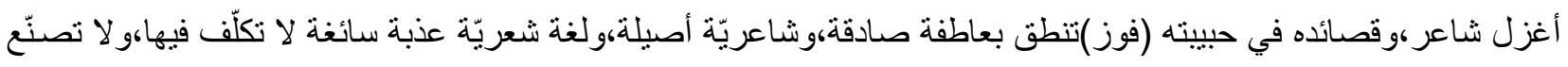

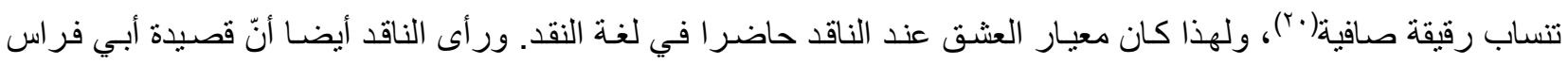

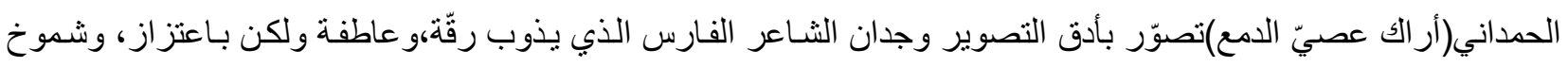

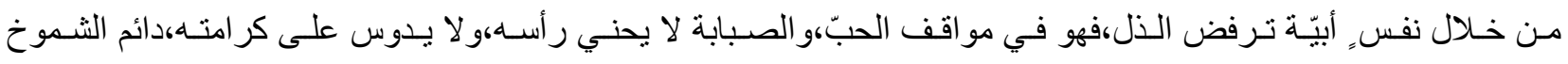

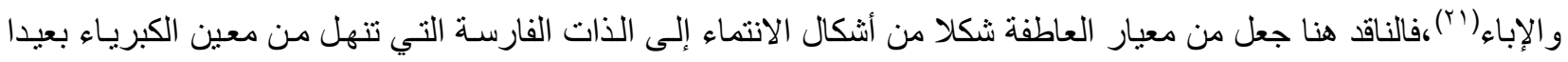

عن الإذلال باسم الحب،و التوسّل الرخيص بالمحبوب لتسمو العاطفة مع أخلاق الفروسيّة التي تحتكم إلى منطق الإنصاف. وكانت قصيدة (لبنى) للثاعر قيس بن ذريح بر أي الناقد تمور برقة،وجز النة، وعاطفة صسادقة مشبوبة،وتبدو بتعبير

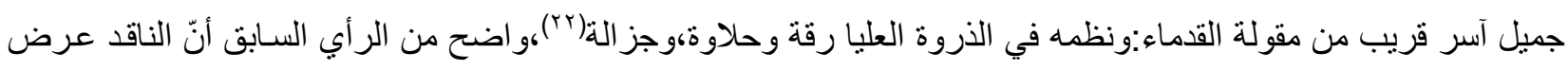

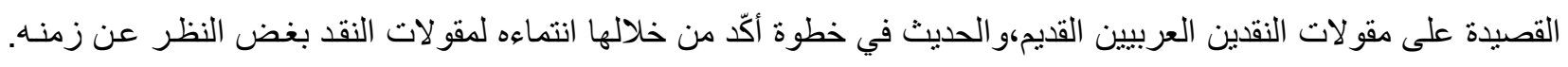

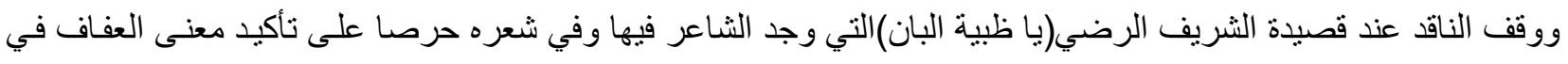

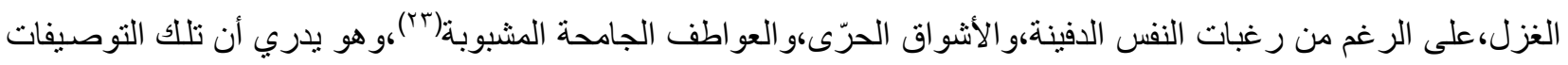
ما كانت إلا بسبب منزلة الثاعر الدينيّة:

\section{$-190$.}




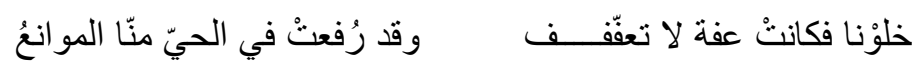

سلو ا مضجعي عنّي و عنها فإنتّا رضينا بما يخبرن عنّا المضاجعُ(؟) و الو اقع أن للشريف الرضي قصائد أخرى لم يستطع فيها إخفاء عاطفته الحرّى كما في قوله:

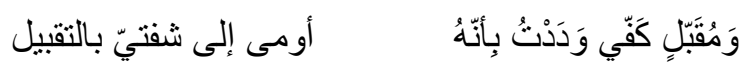

ووجد الناقد أنّ المتأمل في قصيدة ابن زريق(قمر في بغداد)لا بد أن يكتشف رقّة التعبير فيهاهوصدق العاطفة،وحر ارة

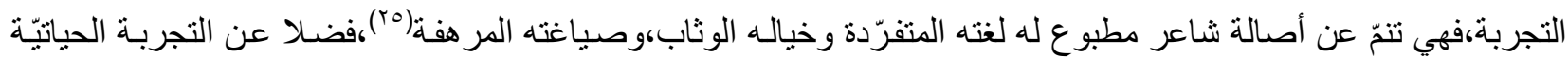
القاهرة،فالثاعر إزاء شوق عارم،و عاطفة جيّانثة مصدر هما حبّ الزوجة البعيدة التي كانت في يوم مـا سكن الثـاعر ، و أنسـه.

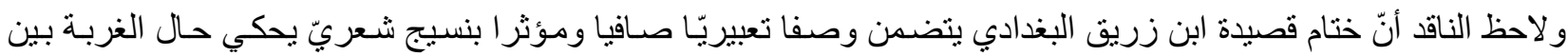

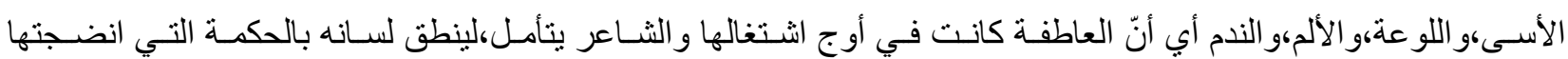
التجربة،وو اشر اق القلب بالدموع(r؟r). بايجاز شديد نرى أنّ الناقد (شوشة) في قراعته لخطاب الثناعر العاثقق ربط بين العشق،وصدق العاطفة،والثـور

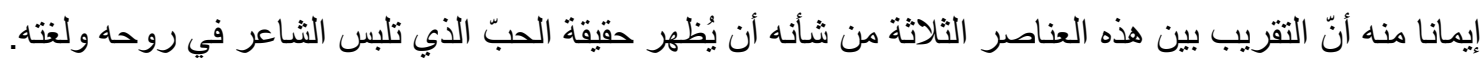

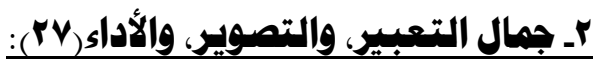

يريد الناقد بجمال التعبير نَظْمَ الكلام الذي يحيل على دقّة اللسان من خلال (تعالق) الدو ال المنتجة للمداليلببسبب من

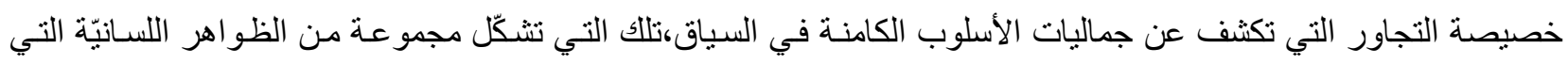

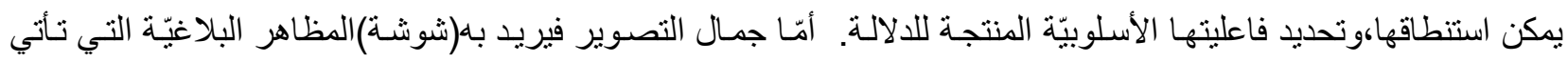

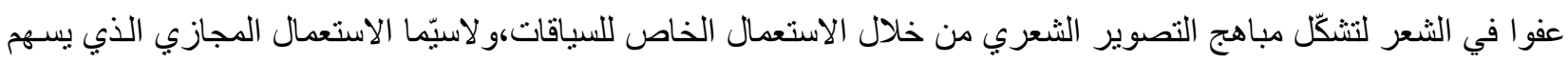
في تقديم المعنى برونق التميّز،بقي أن نقف عند الأداء بوصفه قدرة الثناعر على إنتاج الثُعر بلغة يمكن الاحتكام إليها،ققد تكون

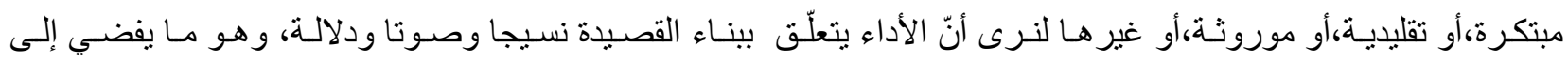

تلقيها،و الاستنناس بما فيها بوصفها نصيّا حاملا لمضامين مميّزة.

لقد جمع الناقد هذه التعبيرات الاصطلاحيّة ليجعل منها معيار ا حاكما يتعلّق بتلقي الثتعر، واختبار أجمله،وقد قدّم من

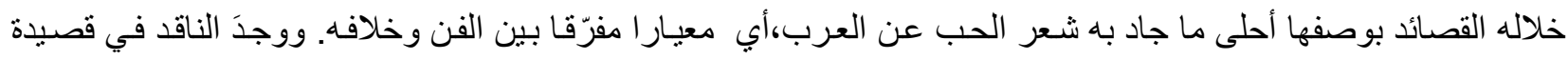

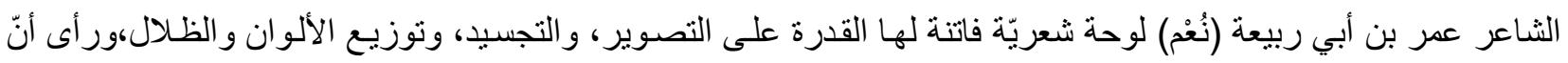

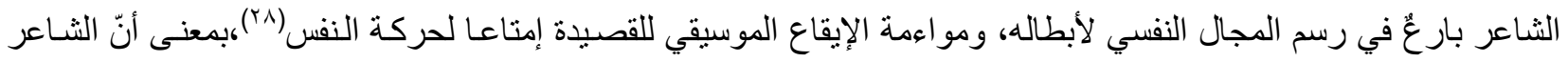

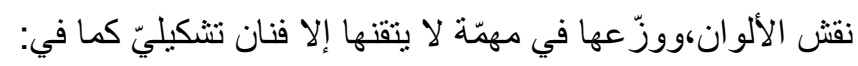

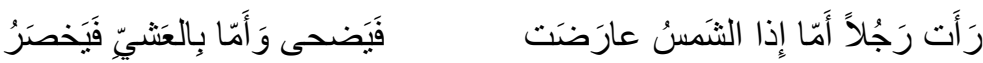

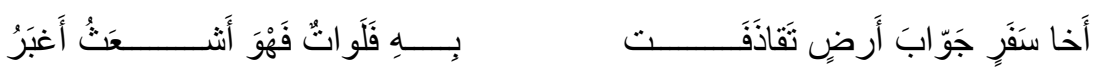

ور أى الناقد في قصيدة بزيد جوّا منرفا وصور ا طبّعة لمن شبّ في رفاهية العيش ونعيمه و هنائه، ورقِّة الطبع التي لا

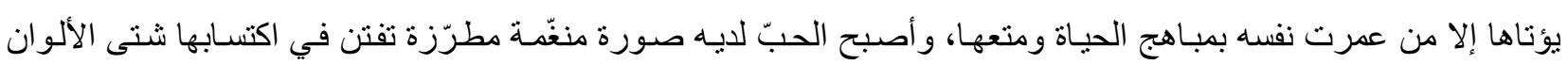

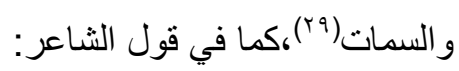

\section{$-197$.}




$$
\begin{aligned}
& \text { خذو ا بدمي ذاتَّ الوشاح،فإنّني ر رأيتُ بعينيّ في أنامِِها دمسي }
\end{aligned}
$$

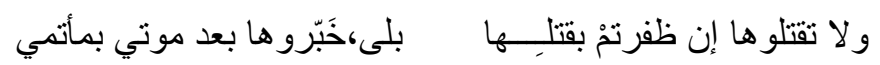

وحين وقف الناقد أمسام قصيدة (وحيد المغنيـة)لابن الرومي وجدها واحدة من عيون قصـائد النشاعر تتطق بقدرتـه

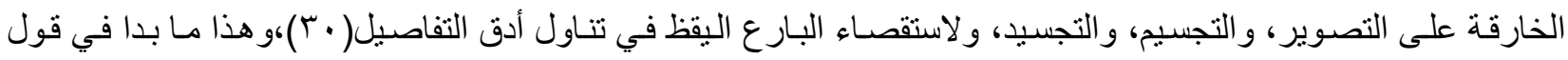
الثاعر:

$$
\begin{aligned}
& \text { شمس دَجْنِ،كلا المنيرين من شم س وبدر من نُورها يستفيدُ }
\end{aligned}
$$

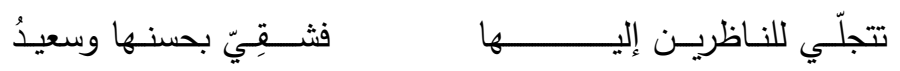

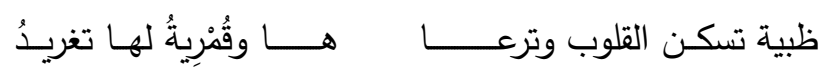

ور أى الناقد (شوشة)في قصيدة دوقلة المنبجي(اليتيمة)تفننا في وصف المحبوبة التي لم ينرك شيئا منها إلا وصفه أدقّ

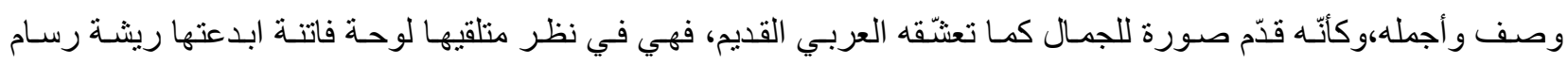
و تمثّل الناقد قصيدة(أضحى التنائي) لابن زيدون فوجدها تتّسم كما هو شعره بالنعومـة، والبر اعـة في التصوير ،تصـوير

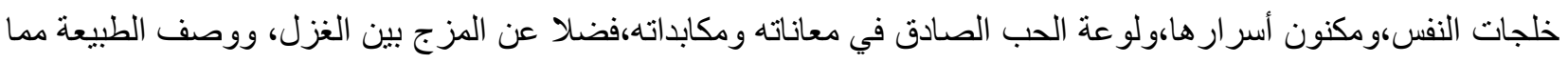

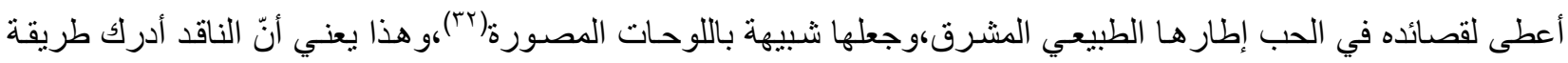

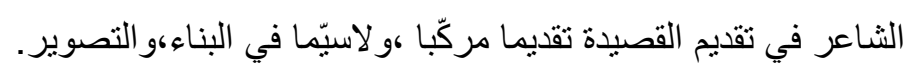
وتأمّل الناقد قصيدة (صلوات في هيكل الحب)لأبي القاسم الثابي فوجدها قد كتبت بلغة شعريّة جديدة رسمت صورة

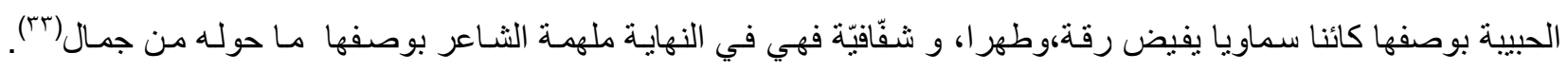

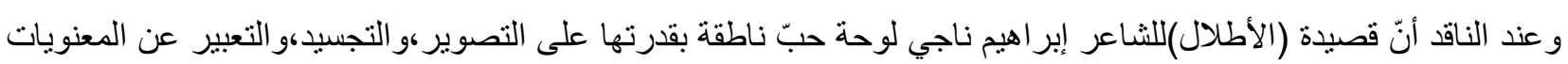

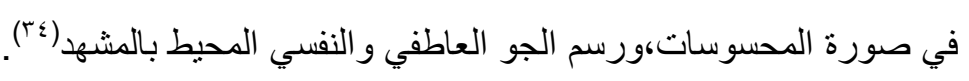
لقد ربط الناقد (شوشـة)بين جمـال التعبير، و التصـوير، و الأداء، و التجسبد الذي هو مـن القضـايا التي أنتارت انتبـاه

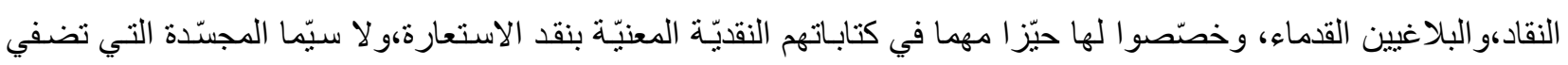

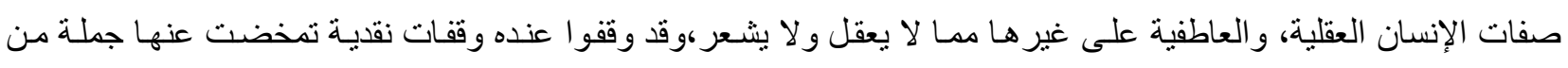

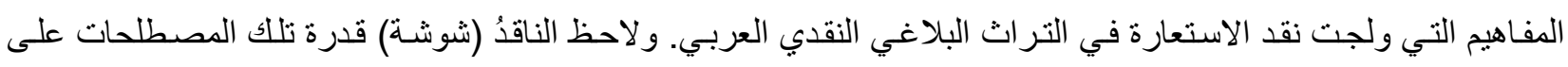
محاورة الأشياء الجامدة، وغير العاقلة، والمعاني التي لا تدرك الا بالذهن عن طريق(الأنسنة)التي تلبس الأشياء صفات الكائن

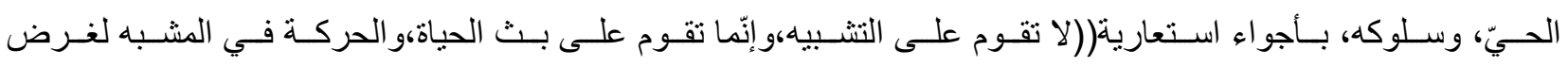

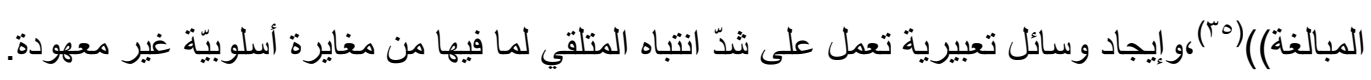
إنّ التجسيد وعي جمالي، وفكري يقود الصورة الأدبية إلى مزيد من الإبداع اللغوي- الجمالي في أطرٍ أسلوبية مغايرة

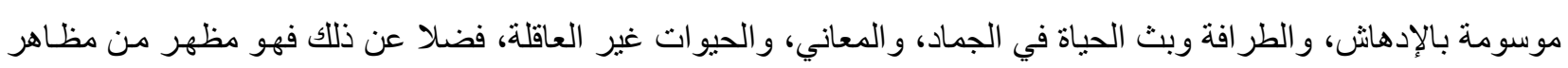
شحذ العقل، وتأكيد إبداعه.

\section{$-19 V=$}




\section{rـ نصنُ شعريَ فاتن(r):}

الفتنة في النصوص يدركها الناقد الجامع بطريقة نفسيّة يكون للذائقة فيها أثر في توجيه الاختيار ،وتثـيل مهار اته

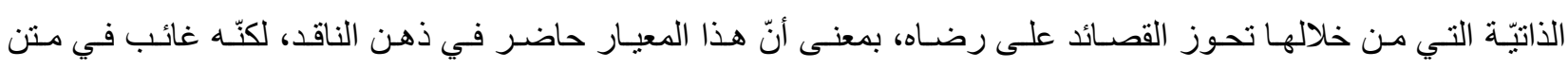

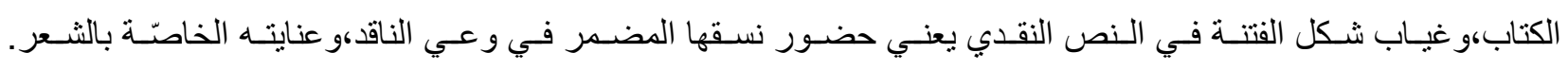

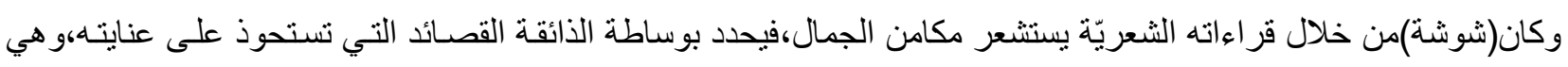

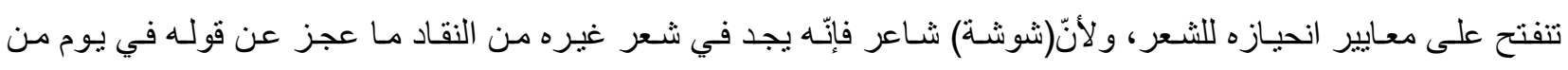

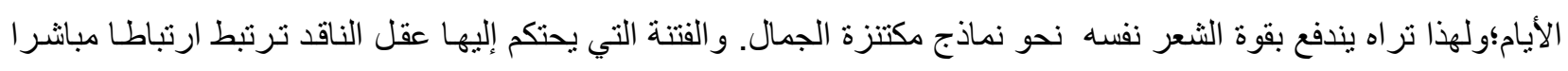

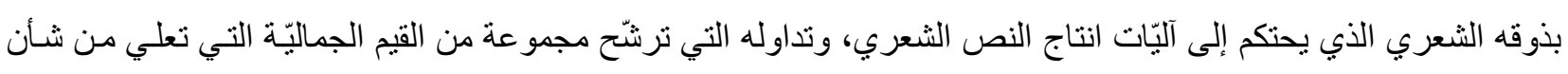

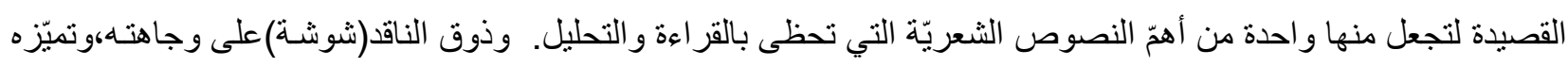

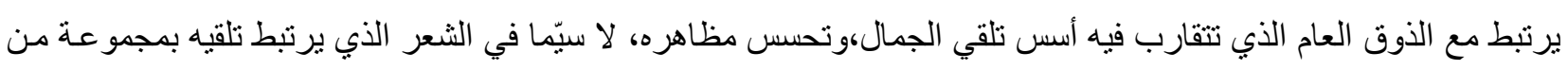
المهار ات المرتبطة بثقافة الناقد أو لا وثقافة بيئته.

\section{همايير أخرى: معري:}

هي معايير التقطها (البحث)من منن الكتاب لم يصرّ ح بها (شوشـة)فقد اكتشفها (البحث)من خلال التدقيق في سياق

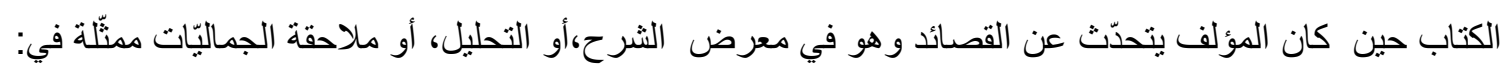

ـ الالغة:

اللغة معمار القصيدة، ونسيجها الذي تنطلق منه الرؤى، و العواطف، ومظاهر الأسلوب، فهي عماد كلّ أدب جميل،

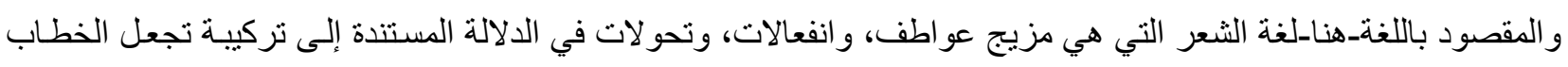

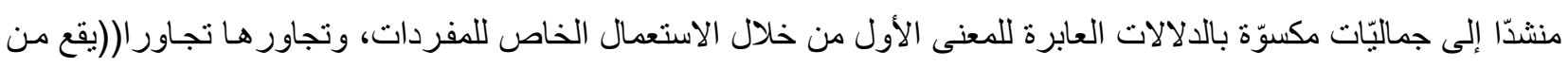

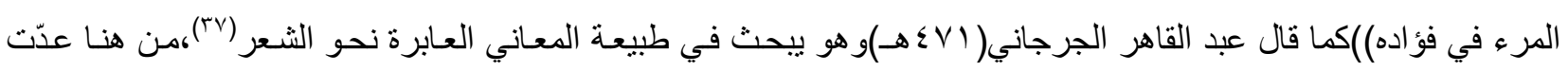

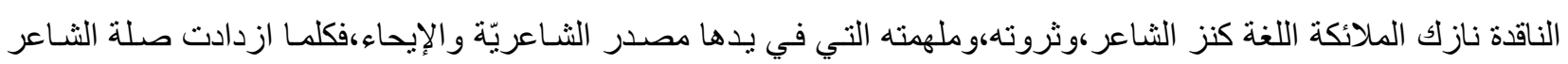

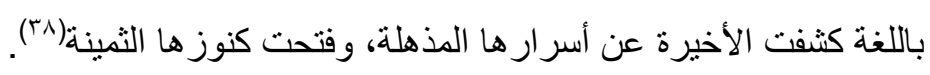

عدّ(شوشة) لغة (المنخّل اليثَكري) في قصيدته (فتاة الخدر)تراوح بين الجزالة و الجيثـان، و الوقع الآسر، وبين

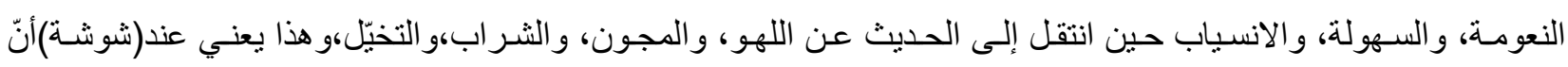

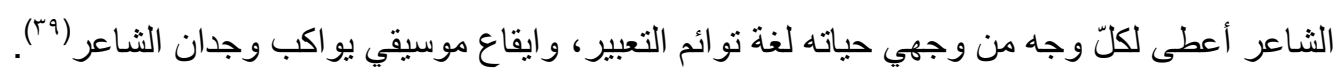
ووجد الناقد في شعر قيس بن ذريح ما وجده في شعر العذريين من رقة، وجز الة، وعاطفة صادقة مشبوبة، وتعبير

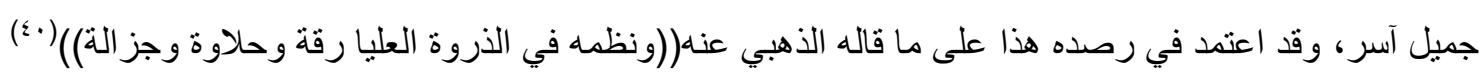

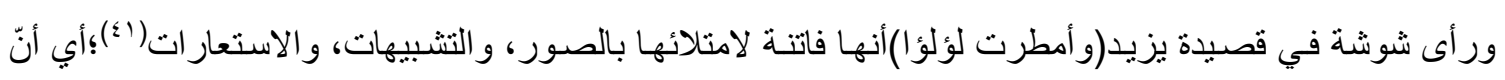

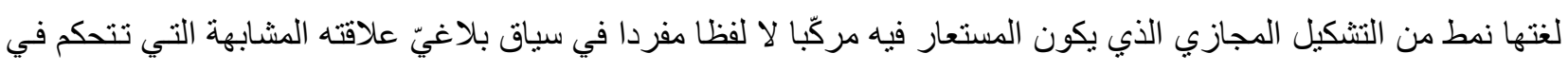

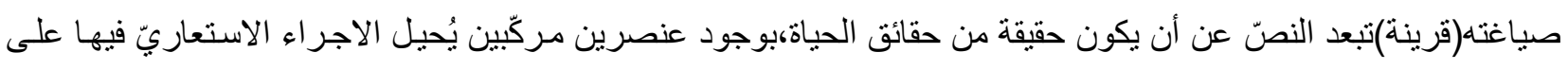

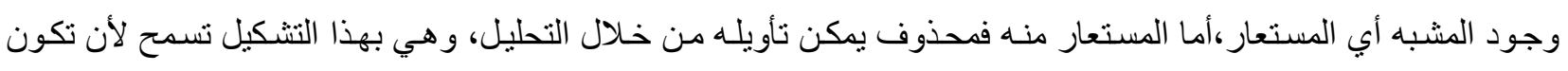

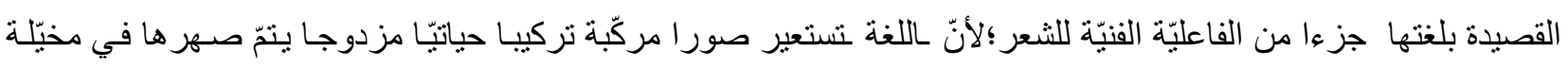

\section{$-191$.}


الثـاعر بوصفها مشبّهات الصورة الأولى التي تنفتح على مداليل أخرى يتحكّم فيها تأويل المتلقي ليشكّل الصسورة الأخرى أي صورة التلقي. أمّا لغـة (الثريف الرضي)في قصيدة (ياظبيـة البان) فهي في صياغة نقيّة مصقولة خالية من الثو ائب بريئة من التكلف، بسبب تهذيب شعره وتتخيل ألفاظه وصيانة ديباجته من عيوب التعبير، أو سقطات اللغة،أو ضحالة المعنى، وركاكة

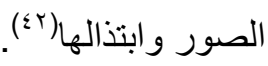

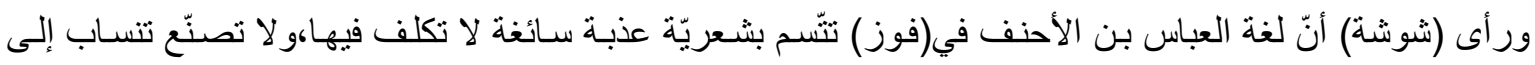

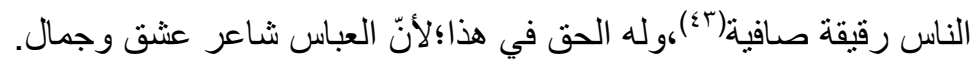
وكان أنّ وقف الناقد عند قصيدة صفي الدين الحلي(مجلس الهيب)فوجدها قبسا متقدا بالثـاعريّة الأصيلة،وصوتا فريد التعبير رائق الأنغام صافي الديباجة قوي السبك(؛؛) ـووجد الناقد نفسه في قصيدة أبي القاسم الثابي(صلوات في هيكل الحبن)

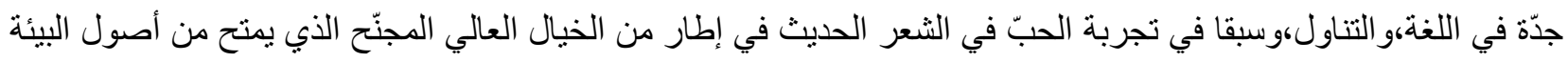

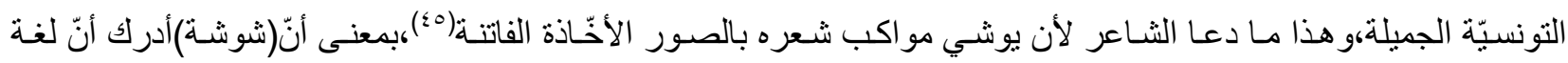
الثاعر تعاصر الوجود،وتمضي قدما نحو تجديد قثرتها. ور أى في لغـة (أقبلي كالصـلاة) للشـاعر علي محمود طـه مذاقا خاصتّا مميّز اومركّبا، فللثـاعر معجم خـاص فريد

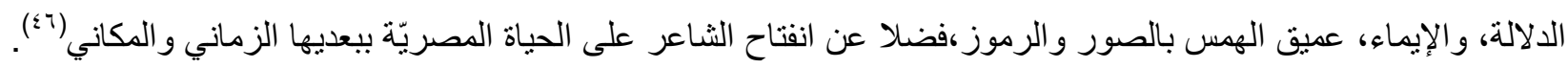
و واضح جدا أنّ عناية الناقد باللغة في القصائد ما كانت عناية تنظير، وتأمل إنّما كانت عناية تحليل قريب من السياقات،

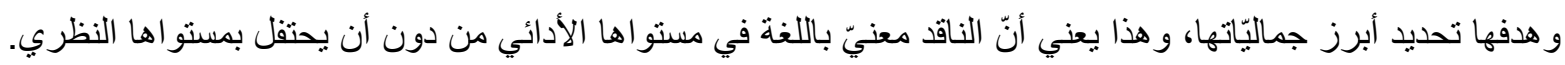

\section{:}

يقترن طول القصيدة عند العرب بالجودة،و هذا يعني أن طول القصيدة يستدعي مزيدا من العنايـة والحذق، و التشكيل،

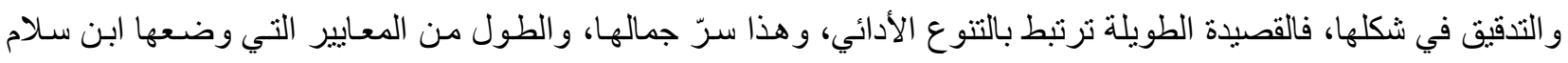

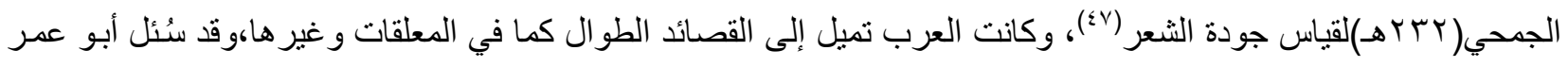

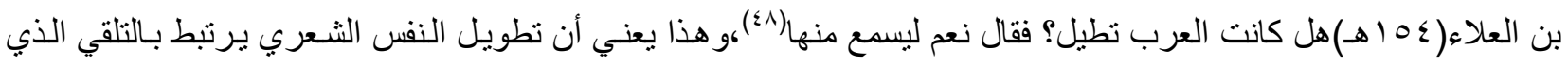

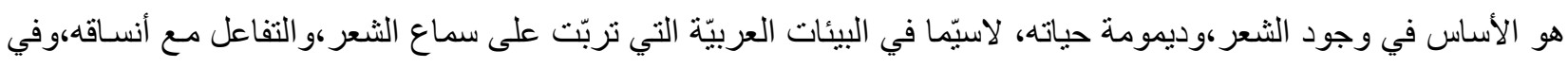

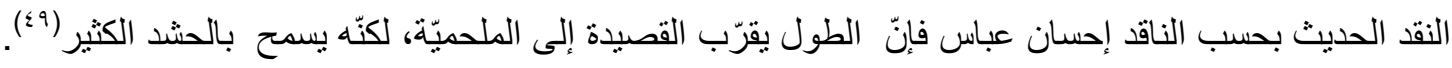
شكّل طول القصيدة عند(شوشة)معيار ار راصدا لاختيارها،و هذا يعني أنّ الطول عنده ارتبط بالجودة والتفرد،فهو دليل قريحة لا تتضب،وبر هان عقل شعريّ مبنيّ على المطاولة ذات السلاسة المرتبطة بالمعنى و المبنى،وقصيدة عمر بن أبي ربيعة

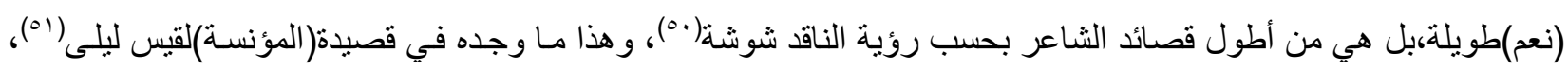

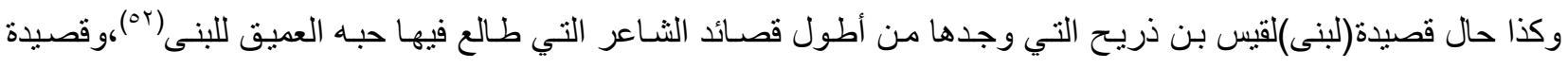

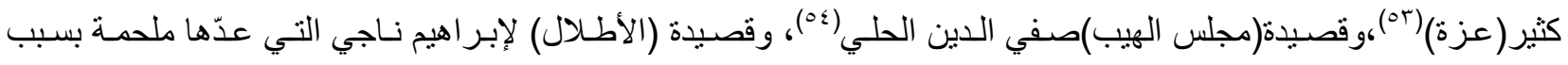


لقد أدرك الناقد(شوشة)بحسّه النقديّ المنفتح على قر اءات متعدّدة للتر اث و المعاصرة أنّ معيار الطول في القصيدة

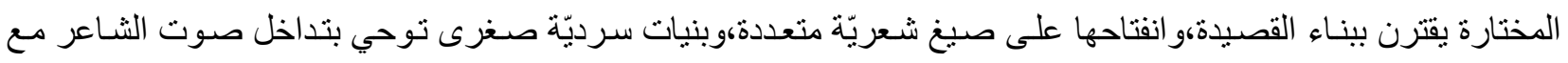

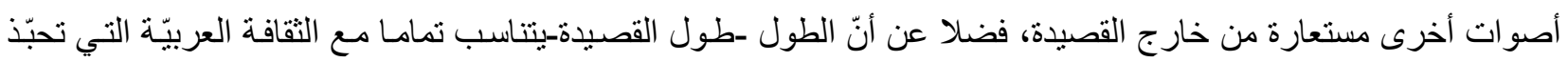
النفس الثعري ذا الثكل المتعدّد،وهذا ما وُجد في أغلب القصائد المختارة.

بـالشهرة:

الثهرةُ معيارٌ غير فنيّ قام عليه جمع قصائد الكتاب،ويعني بـ(شوشة)اشتهار القصيدة، وبلوغها الأسماع،وهو مـا عناه

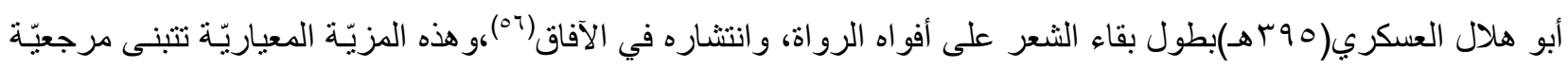

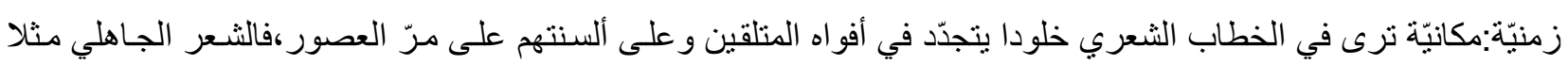

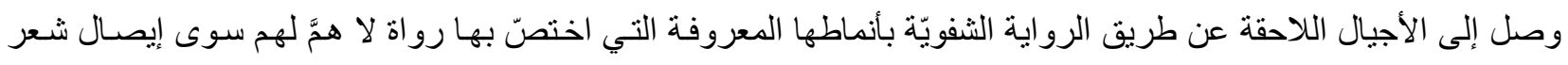

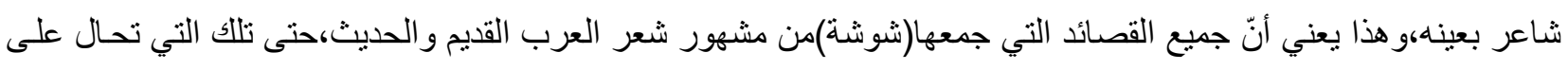

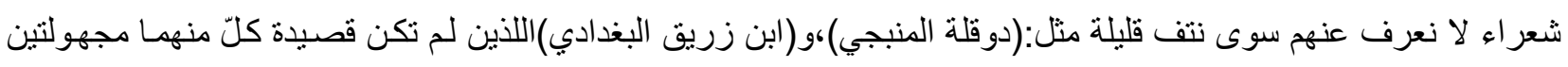

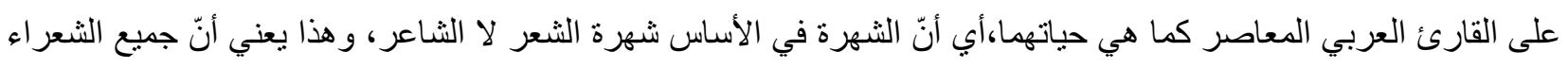

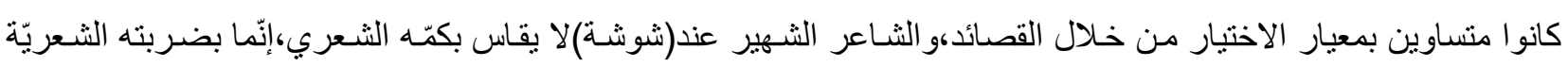
التي قد تكون في قصيدة واحدة لا غير ها. كان الناقد(شوشة)قد اعتمد معيار شهرة القصبدة سببا في اختيار ها،أي مقياسا لتفضيلها على غير هـا، فقصبدة عمر بن

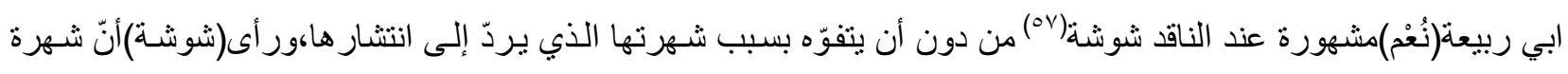

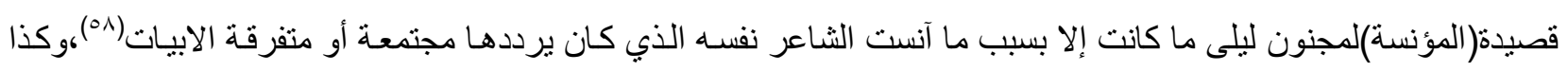

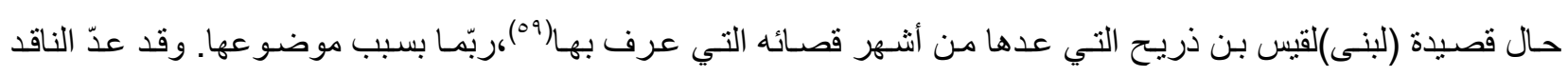

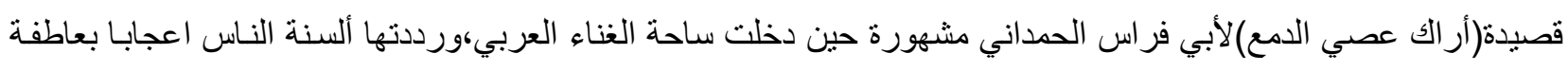

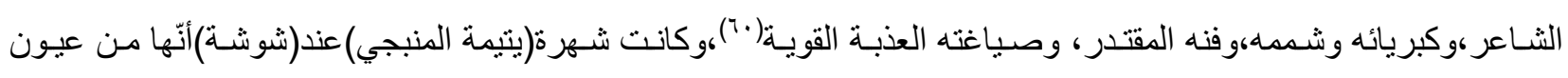

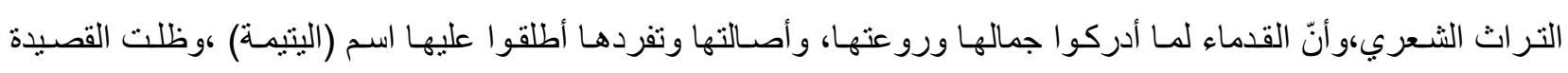

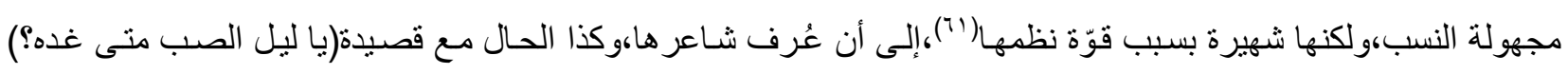
للحصري القيرواني،فهي من عيون الثعر العربي ذاعت شهرتها في أندية الأدب ومجالس الغناء،وتناقلها النساس جيلا بعد جيل بسبب شهرتها(ז) ،وكذا الحال نفسها مع قصيدة(صلوات في هيكل الحب)للثاعر أبي القاسم الثابي التي عدّها(شوشة)من أشهر

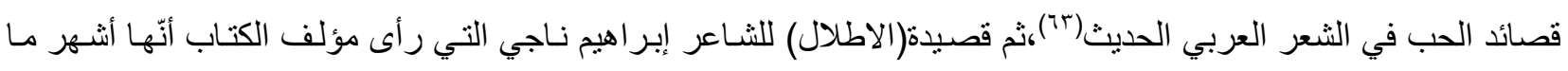

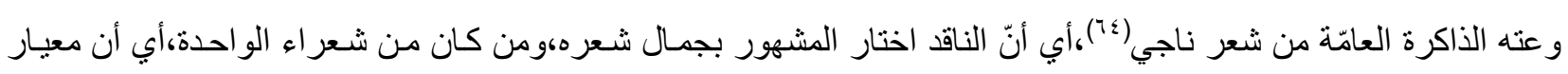

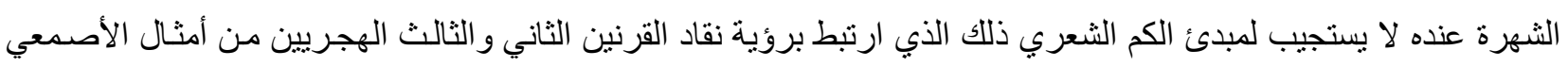
وابن سلام.

\section{عـ هميار ذاتي:}

هو معيار يستند إلى ذوق الناقد الفني و الجمالي ومو هبته الثـعريّة أيضـا تلك التي لا يمكن انكار هـا فـشوشة)شاعر

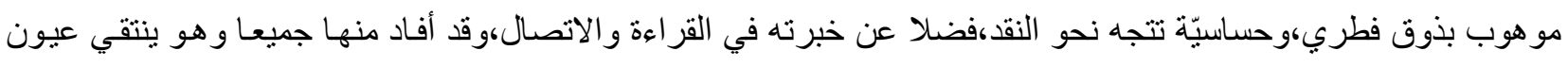

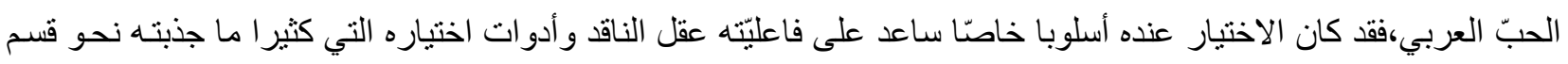


من القصائد دون غيرها،و لا سيّما تلك التي عاش معها زمنـا طويلا،وتأمّلها كثير ا فهي أسبق إلى ذاكرتـه من غير هـ؛ ولهذا صارت العناية بها أكبر (70).

يصرّح الناقد(شوشة)أنّ سبب اختياره قصيدة(أقبلي كالصلاة)للثاعر محمود حسن إسماعيل يردّ إلى سبب ذاتيّ يتعلق

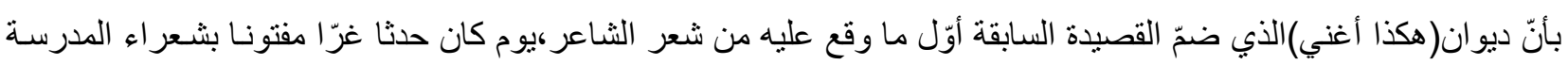

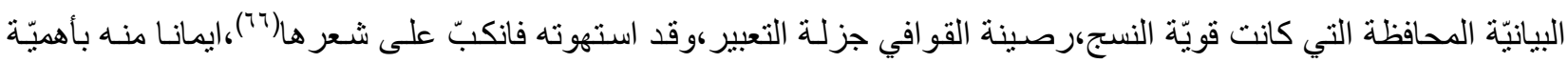
التجربة الثعريّة الني انبثقت من شعراء تللك المدرسة.

إنّ هذا المعيار و إنْ ارتبط بعدد من المسوّ غات عند الناقد مثل:جمال الموضوع الذي يهيمن على أجو اء القصيدة،ووفرة المظاهر البلاغيّة التي تعمل على تقديم القصيدة تقديما سلسا وجميلا،وقبل هذه وتللك اللغة والأسلوب اللذان يعملان على نتئ تشكيل

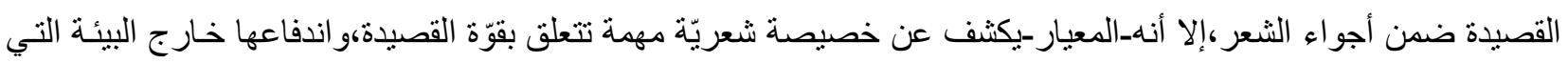
ظهرت فيها،وطر ائق تلقيّها عند الناقد.

خصائص المنهج:

هي مجمو عة من الإجر اءات،و الخطوات العمليّة المنهجيّة التي استعملها الناقد، وهو يديم صلته النقديّة بمجموعة

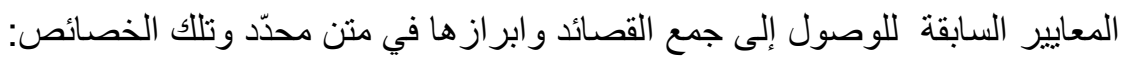

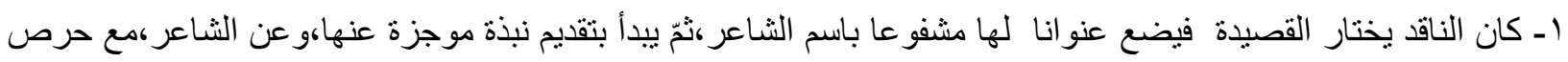

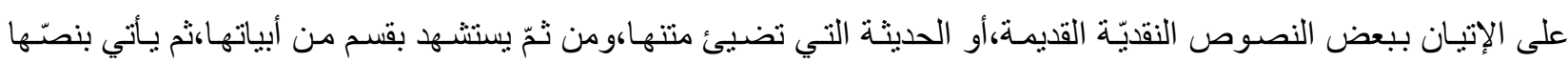

r- حرص الناقد على أن يفكّلك القصيدة إلى جزئياتها الموضو عيّة،و الفنيّة تسـهيلا لقر اءتها، وتحديد أبرز معالمها النصيّة و الجماليّة،وه هذا التفكيك يسهم في قر اعة القصيدة وتحديد أبرز معالمها النصيّة. r- اتخذ الناقد(شوشة)من أشتعار القدماءوه المعاصرين مادة للجمع؛أي أنّه وستع من دائرة الاختيار ، ولم يقتصر على القدماء من

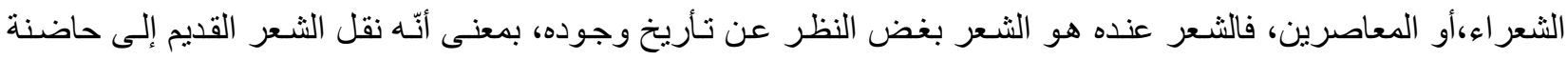

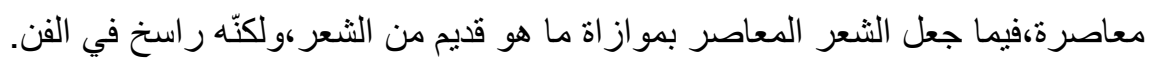

ع -كان الناقد(شوشة)ينتقي القصائد لا الأبيات،بمعنى أنه يأتي بالقصيدة كاملة،ور لا يتعسّف في الاستغناء عن بعض أبياتها، كما

فعل سابقوه ممن جمع القصائد ناقصة. هـلم يتلذخل الناقد في نصوص الثعر اء تبديلا،وأو تغييرا بما يُلائم ذائقته و أفكاره، وهذا يعني أنّه كان أمينـا وحريصـا على نقل القصائد كما هي.

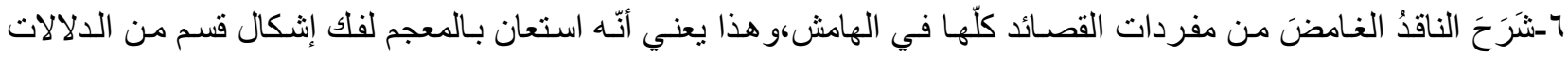
الصعبة و لا سيّما في القصائد القديمة. V-Vلم يتحيّز الى شعر اء بعينهم على حساب شعر اء آخرين، و إنّما نظر إلى الجميع بعين واحدة، فهو ناقد منصف كان هدفه تخيّر القصائد بعيدا عن سلطة المكان في عاطفته. 


\section{الخاتمة:}

1 - إنّ الناقد (شوشة)في مقدمة كتابه اقترح عددا من المعايير النقديّة الني بنى من خلالها اختيار اته أجملها في أنّه يبحث عن:

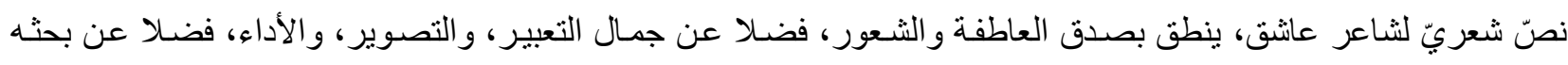

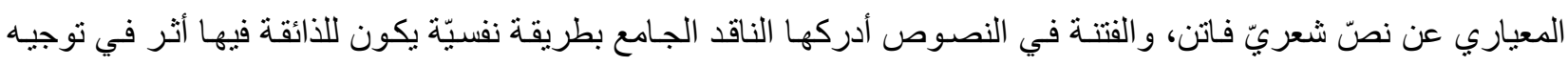

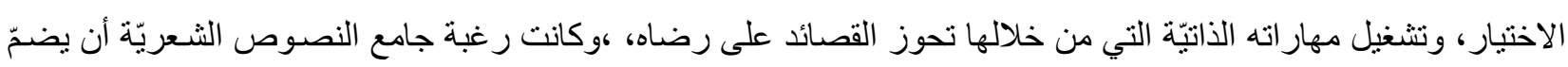

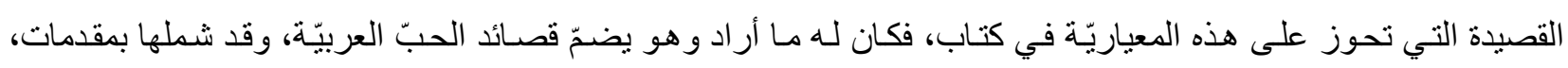

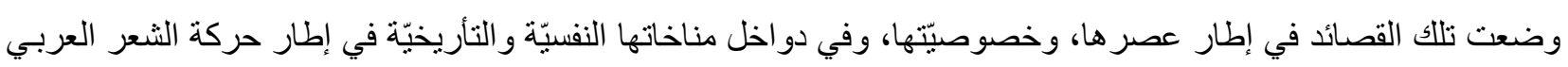

ودور انه المستمر.

ك- تحدّت في متن الكتاب عن معايير أخرى، وهو يبحث في دلالات الحب شـارحا ومعلّلا،وهي لا تقل أهيّة عمـا قـال في معايير المقدمة، وقد أجملها في: اللغة، وطول القصيدة، والثيل والثهرة. بـ وقد كثف البحث عن مجموعة من الإجر اءات، والخطوات العمليّة المنهجيّة التي اتَّعها الناقد،وهو يديم صلته النقديّة بالمعايير السابقة للوصول إلى جمع القصائد، وابراز ها في منن محدّد.

\section{هوامش البحث}

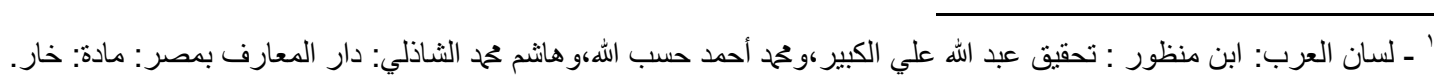

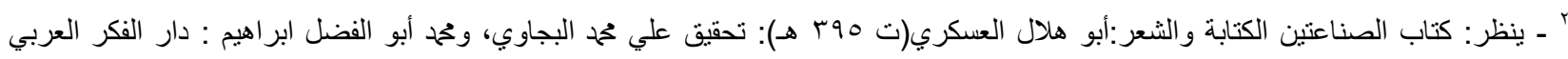

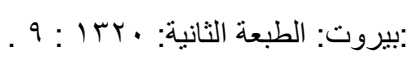

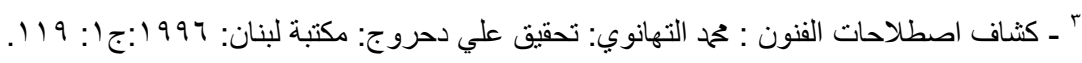

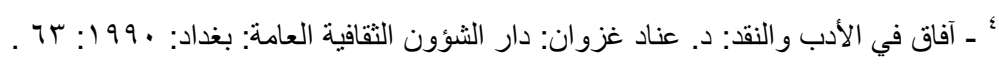

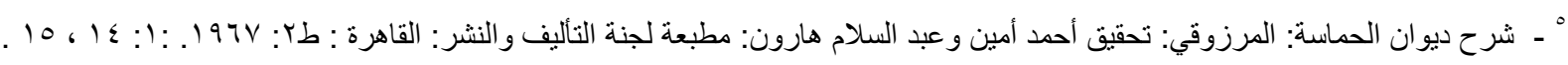

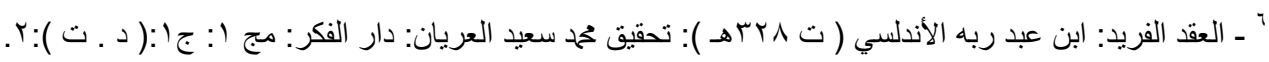

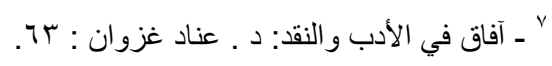

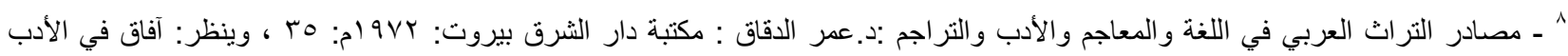
و النقد:01.

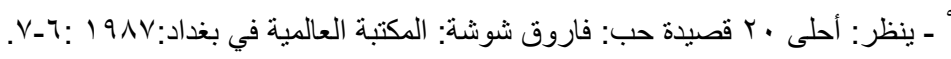

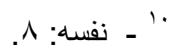

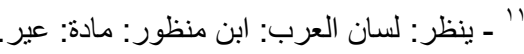

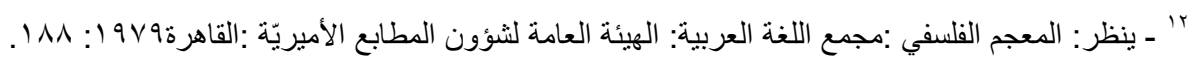

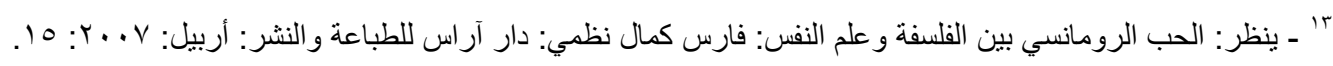

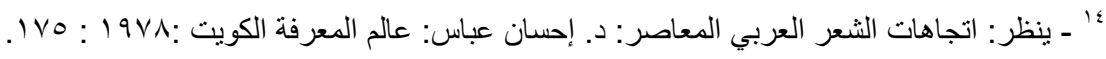
ا 10

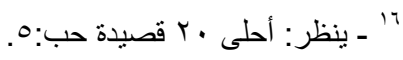

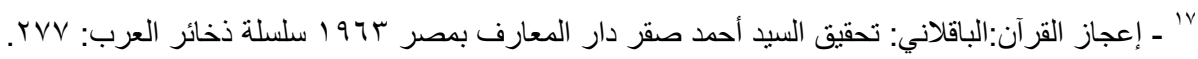

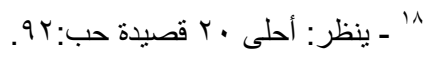

. $94:{ }^{19}$

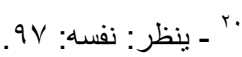




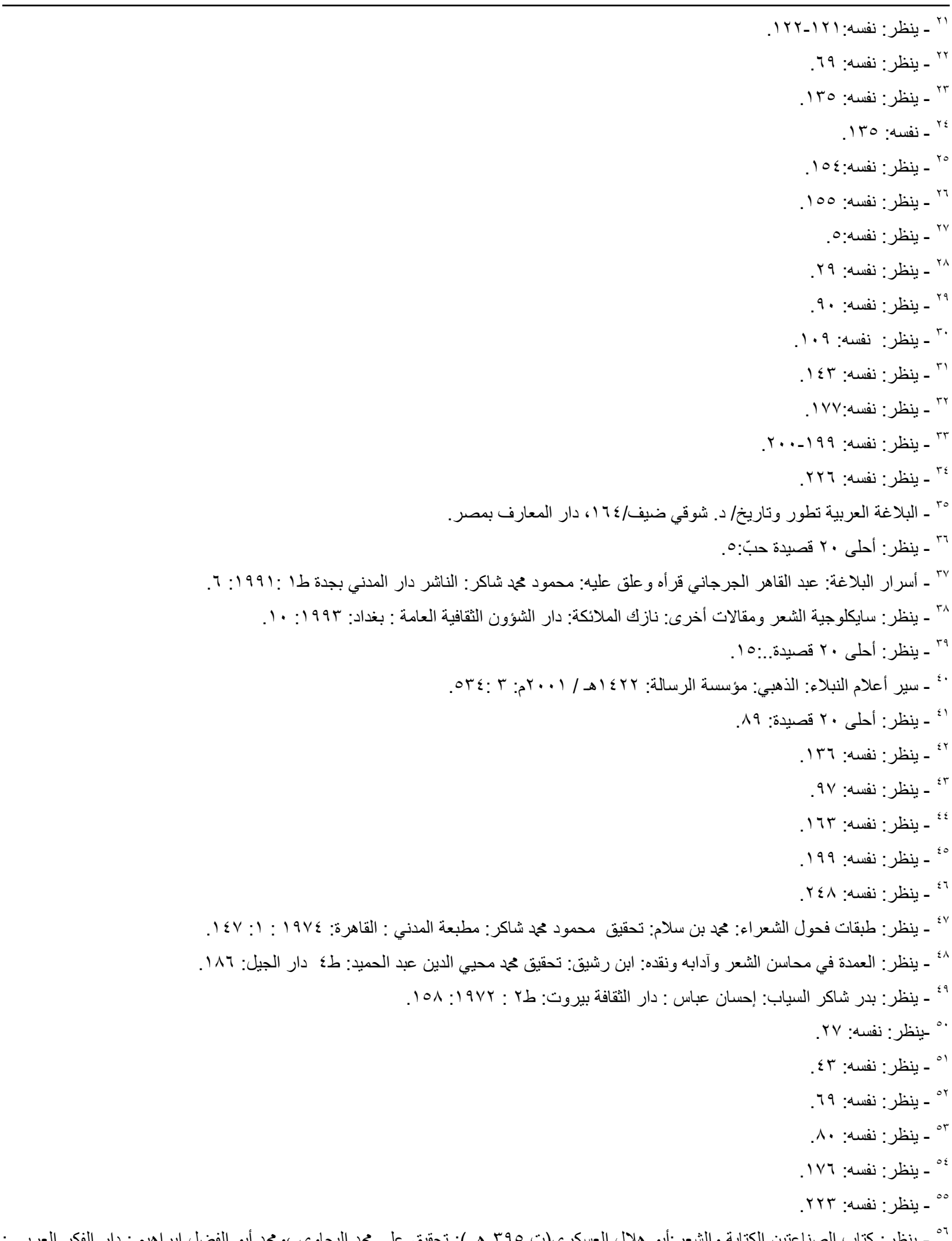

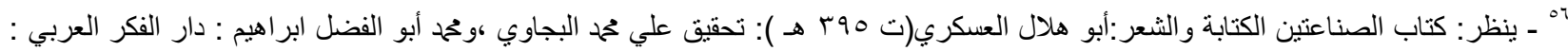

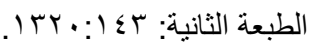

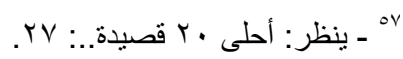

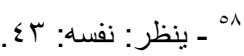




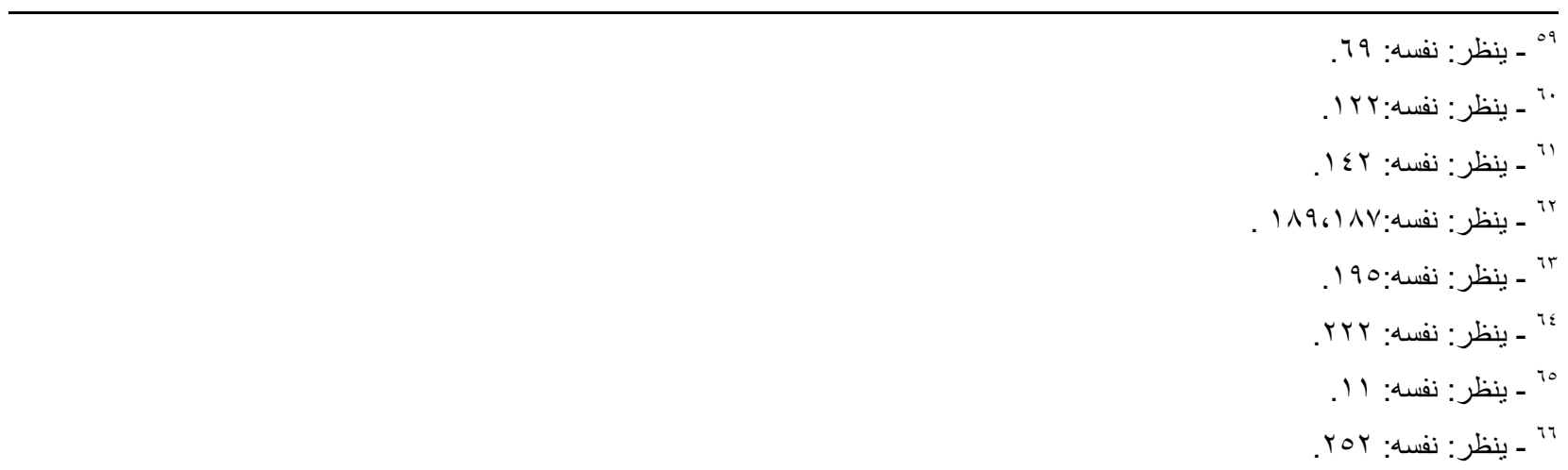

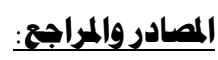

1 ـ آفاق في الأدب والنقد: د. ـ. عناد غزوان: دار الثؤون الثقافية: بغداد: . 199.

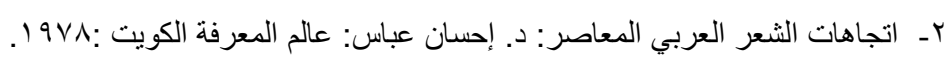

rـ أحلى • r قصيدة حب: فاروق شوشة: المكتبة العالمية في بغداد:طا : 191v.

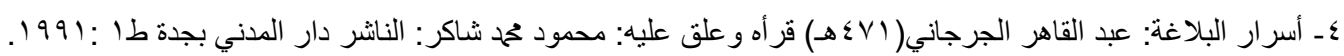

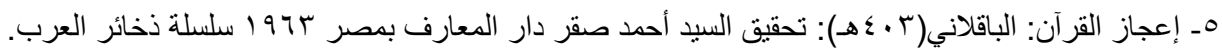
ד- بدر شاكر السياب: د. إحسان عباس: دار الثقافة بيروت:طץ : IVY I. V- البلاغة العربية تطوّر وتاريخ/ د. شوقي ضيف، دار المعارف بمصر. ^ـ الحب الرومانسي بين الفلسفة وعلم النفس: فارس كمال نظمي: دار آراس للطباعة و النشر: أربيل: V. . r. 9- سايكلوجية الثعر ومقالات أخرى: نازك الملائكة: دار الثؤون الثقافية العامة : بغداد: بو9 أ.

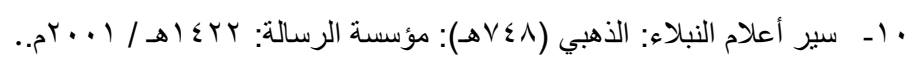

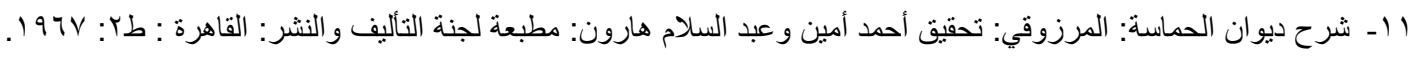

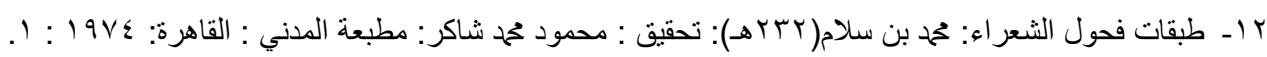

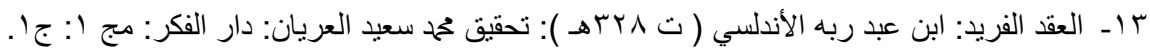

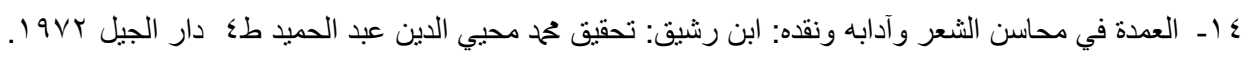
10ـ كتاب الصناعتين الكتابة والثعر:أبو هلال العسكري(ت 90ب هـ ): تحقيق علي ححم البجاوي ،ومحمد أبو الفضل ابر اهيم : دار الفكر العربي : الطبعة

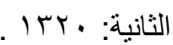

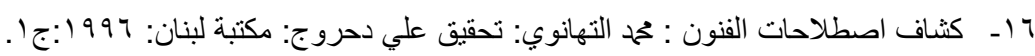

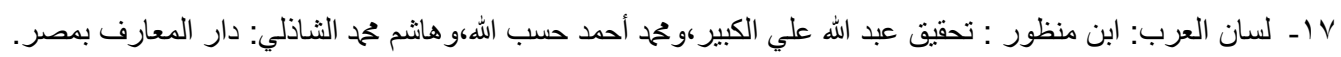

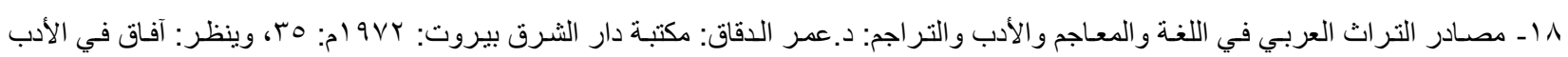
و النقد. 9 1 ـ المعجم الفلسفي :مجمع اللغة العربية: الهيئة العامة لثؤون المطابع الأميريّة :القاهرة 9 ـو ـ 